\title{
Estado del conocimiento sobre resignificación de políticas en materia de autonomía de gestión escolar en el marco de los Consejos Técnicos Escolares State of the Knowledge on the Resignification of Policies Related to School-based Management in the Framework of School Technical Councils
}

\section{RESUMEN}

El presente estado del conocimiento se propone revisar la literatura relacionada con la resignificación de políticas en materia de autonomía de gestión escolar, orientada, en específico, al contexto de los Consejos Técnicos Escolares. Se revela que, si bien los primeros estudios provienen de experiencias internacionales, su punto más alto se da en 2017, con investigaciones mexicanas realizadas tras el lanzamiento de los documentos relativos a la Reforma Educativa 2013. Aunque los dos principales campos de indagación detectados son la política y la gestión educativas, ninguna de las investigaciones revisadas plantea la relación patente que existe entre ambas, incluso si, en la práctica, los sistemas educativos nacionales esperan que éstas se articulen entre sí. Del mismo modo, tampoco se analizan las interacciones propias de la micropolítica de la escuela y sus efectos en la gestión educativa, en especial en lo referente a la autonomía de gestión y a la organización escolar. Estos vacíos son de interés para investigaciones futuras sobre el entendimiento de dichas interacciones y para visibilizar el papel fundamental que desempeñan los Consejos Técnicos Escolares en la puesta en acto de reformas y políticas educativas.

Palabras clave: autonomía de gestión escolar, política educativa, educación básica, consejos técnicos escolares, micropolítica de la escuela
Alejandra Luna Guzmán

Universidad Iberoamericana, MÉXICO alejandra.luna@ibero.mx

\section{ABSTRACT}

This state of the knowledge reviews the literature related to the resignification of policies in the field of school-based management, especially focused on the context of School Technical Councils. It reveals that, although the first studies come from international experiences, their highest peak is in 2017, with Mexican research carried out after the documents related to the educational reform 2013 were launched. Although the two main fields of inquiry detected are educational policy and educational management, none of the reviewed researches sets forth the patent relationship between the two, while national educational systems expect them to articulate each other. Similarly, the interactions of the school micropolitics and its effects on educational management are not analyzed, especially concerning school-based management and school organization. These gaps are of interest for future research on the understanding of these interactions and to make visible the fundamental role played by School Technical Councils in the implementation of educational policies.

Keywords: school-based management, educational policy, basic education, school technical councils, school micropolitics 


\section{INTRODUCCIÓN}

El presente estado del conocimiento se desprende de una investigación cuyo objetivo es realizar un estudio cualitativo sobre la manera en que se resignifican las reformas y políticas en materia de autonomía de gestión escolar, orientado, en específico, al contexto de los Consejos Escolares en escuelas públicas a nivel básico en México. La alineación de la investigación marco es política educativa, la cual "tiene como principal objetivo contribuir al análisis, monitoreo y debate público sobre los principales retos que enfrenta el diseño, implementación y evaluación de las políticas y programas educativos en México" (INIDE, 2018).

Dado que uno de los focos de esta línea de investigación es analizar "el rol que juegan distintos actores políticos, sociales y educativos en la conformación de la agenda de políticas y programas educativos" (INIDE, 2018), se consideran las dimensiones tanto de las reformas y políticas cuanto de los Consejos Técnicos Escolares desde los aspectos macro-institucional y micro-institucional, así como los distintos factores y expresiones de resignificación de la política educativa en la micropolítica de los Consejos Escolares y cómo se decantan hacia la práctica cotidiana escolar. Asimismo, se atiende también la línea de investigación sobre calidad y equidad en educación básica, la cual tiene como reto contemplar los factores pedagógicos, sociales, culturales, económicos, políticos y administrativos que afectan dichas dimensiones. Con ese objeto, se consideran las políticas educativas que han dado forma a los Consejos Escolares, así como la dimensión político-pedagógica de las reformas y políticas en la práctica de los cuerpos colegiados.

\section{ANTECEDENTES}

Para comprender los procesos de resignificación de reformas y políticas en materia de gestión escolar en el marco de los Consejos Escolares, se habrá de partir, en primera instancia, de un antecedente primordial para las reformas del cierre del siglo XX en México y para la configuración de los Consejos Escolares en sus distintas formas. Se trata del Acuerdo Nacional para la Modernización de la Educación 
Básica y Normal (ANMEB), de 1992, que dio normatividad a la participación social y marcó un hito hacia la autonomía de gestión escolar.

Previo al ANMEB, sin embargo, se han de mencionar los Acuerdos Números 96, 97 y 98, que establecen la organización y funcionamiento de las escuelas primarias, secundarias y secundarias técnicas (DOF, 1982), en los cuales surge la figura de los Consejos Escolares bajo la nomenclatura Consejo Técnico Consultivo, que se transformaría, a partir de la Reforma 2003, en el Consejo Técnico Escolar (CTE), y en el cual se delinea el primer marco normativo que determina su funcionamiento.

En cuanto a los antecedentes históricos del ANMEB, Latapí (2004) documenta y analiza dicho acuerdo y las políticas de Estado que en torno a éste llevó a cabo cada secretario de Educación Pública. Jiménez y Perales (2007) destacan la necesidad de reestructuración al interior de las escuelas tras la entrada en vigor del ANMEB, y la manera como se suceden los procesos sociopolíticos en el ámbito escolar, en especial en cuanto a la gestión escolar y la profesionalización de los maestros.

Por otro lado, es muy importante aclarar la relación que prevalece entre la figura de los Consejos Escolares y la participación social. Si bien los actores que inciden en la educación desde el punto de vista social son todos aquéllos alrededor de los educandos, desde la historia de la política pública se observa que el Estado ha sido quien busca determinar las funciones y el grado de injerencia de cada uno de los actores en la educación formal. Es de conocimiento público que gran parte del siglo XX la educación formal estuvo por completo bajo control del Estado. Latapí (2004) señala que ello, en asociación con el Sindicato Nacional de Trabajadores de la Educación (SNTE) -sumado, a partir de los ańos cincuenta, a una cultura individualista y poco cívica-, limitó al máximo la participación social en la misma. Esta carencia se fue haciendo cada vez más patente, hasta que al conformarse el ANMEB, el entonces secretario de Educación Pública, Ernesto Zedillo, logró que se incluyera la participación social en el acuerdo.

De esta manera, la Ley General de Educación publicada en el DOF en 1993, que siguió vigente hasta septiembre de 2019, establece la participación social como un medio de distribución de la función social educativa. A partir de entonces, se reconoce como una 
obligación y un derecho de los padres y tutores estar involucrados en el proceso educativo de sus hijos y tutorandos.

La participación social siguió un largo proceso de políticas y acuerdos que fueron del nivel nacional, con el Consejo Nacional de Participación Social (Conapase), ${ }^{1}$ al estatal, municipal, hasta el de la comunidad y el centro educativo. De esta manera, en las escuelas se crearon dos figuras, los Consejos Escolares de Participación Social (CEPS) y los Consejos Técnicos Consultivos, que habrían de transformarse, finalmente, en los Consejos Técnicos Escolares (CTE). Perales y Escobedo (2016) identifican a los CEPS como parte del esfuerzo por mejorar la participación social en las escuelas públicas. Señalan que buscan promover un diálogo constructivo y corresponsable en relación con la administración y la organización de las escuelas y con el involucramiento de varios miembros de la comunidad educativa.

Asimismo, el estudio de Santizo (2011) sobre la política de participación social, señala que este proceso implica modificar la organización escolar para lograr una mayor coordinación y colaboración entre los actores. Se detecta que hay vacíos en las políticas de participación social que debe cubrir la política educativa. Olivo, Alaníz y Reyes (2011) se refieren a la figura de los Consejos Escolares de Participación Social (CEPS) desde un enfoque de gobernabilidad y gobernanza, destacando que son insuficientes para saber lo que en realidad pasa al implementarlos en las escuelas, en específico, si empoderan a los actores escolares o no. Concluyen que es necesario considerar a cada CEPS desde sus particularidades históricas y culturales.

Por su parte, se puede considerar que los CTE pertenecen a la última generación de ese largo proceso de políticas y acuerdos en materia de participación social. Tras su creación formal, las funciones de los CTE se fueron transformando y se les llegó a utilizar como un medio para la evaluación docente dentro del programa de Carrera Magisterial. No fue sino hasta el sexenio de Vicente Fox cuando se les comenzó a concebir con fines de "involucramiento y colaboración para el mejoramiento de la calidad [educativa]" (Latapí, 2004, p. 319).

La calidad educativa se abanderó como el quehacer de la Reforma Educativa 2013, impulsada por el presidente Enrique Peńa

\footnotetext{
${ }^{1} \mathrm{Si}$ bien la nomenclatura actual los identifica como Conapase, en la literatura se les puede encontrar, asimismo, como Conapas.
} 
Nieto desde su toma de protesta, el 1 de diciembre de 2012. Así lo corroboró la inclusión del concepto en el artículo $3^{\circ}$ constitucional que, en coordinación con la modificación al artículo 73 sobre el Servicio Profesional Docente, puso de manifiesto el papel central de los docentes en el aseguramiento de dicha calidad, si bien de manera un tanto acusatoria. Sobre estos dos factores se centró la atención tanto de los maestros en servicio, como de la sociedad, los investigadores y los medios de comunicación en torno a esa reforma. Sin embargo, los documentos oficiales afirmaban que "para materializar el nuevo planteamiento pedagógico, se parte de una nueva visión que pone la Escuela al Centro del sistema educativo, como espacio donde convergen todos los recursos y esfuerzos de los distintos actores" (SEP, 2016a). Dicha visión buscó lograr que la Reforma Educativa llegara a los salones de clase, poniendo el sistema al servicio de escuelas con autonomía de gestión (SEP, 2016b).

La autonomía de gestión escolar, para los fines del presente documento, se considera -en consonancia con el artículo editorial de la Revista Mexicana de Investigación Educativa de mayo de 2003 (8, p. 18) sobre descentralización, regulaciones y modelos de autonomía en escuelas de Buenos Aires, Argentina y São Paulo, Brasil-, como la capacidad legal de tomar decisiones propias en dominios de gestión y maniobra institucional. Sobre este aspecto, Namo (1991) ubica, a principios del decenio de los noventa, el inicio de una revolución que coloca a la institución escolar al centro del quehacer educativo:

Es ésta una revolución aún poco perceptible para algunos educadores y estudiosos de la educación, en especial en América Latina; pero el proceso está comenzando -con ritmo lento todavía- con posibilidades de que se acelere en los próximos años, momento en el que provocará transformaciones significativas en las formas de pensar y de efectuar la gestión de los sistemas de enseñanza (Namo, 1991, p. 7).

La autora identifica este proceso como un resultado indispensable, dada la inoperancia de un modelo centralista y vertical, pero subraya la necesidad de que se parta de ciertos prerrequisitos para que la autonomía sea efectiva. A saber, evitar males intrínsecos al centralismo, como el crecimiento anormal o "gigantismo", los intereses 
clientelistas, corporativos e ideológicos, así como la incorporación de mecanismos como la evaluación externa de resultados educativos, formas de financiamiento que aseguren una mejora en la enseñanza dentro de las escuelas, lo cual supone un conocimiento cuidadoso de la estructura de costos del sector educativo (Namo, 1991, p.13).

Por su parte, Zorrilla (2002) identifica las tensiones posteriores a la firma del Acuerdo Nacional para la Modernización de la Educación Básica (ANMEB) en 1992, con el cual se concretó tanto en lo jurídico como en lo administrativo la descentralización del Sistema Educativo Mexicano. Entre dichas tensiones, destaca que la autonomía fue parcial, ya que el gobierno mantuvo mecanismos centralizadores como la evaluación, además de que, en realidad, no pasó a los centros educativos, sino a los gobiernos de los estados. Por su parte, Jiménez y Perales (2007) analizan las reformas educativas en México posteriores al ANMEB, que implicaron una "nueva gestión" de las escuelas públicas, incluida la oportunidad de la participación democrática, el trabajo colegiado y proyectos escolares definidos por los agentes involucrados. Se detecta que la gestión se vincula con roles construidos históricamente y se materializa en posturas, territorios y mitos que los actores educativos ponen en juego en su práctica cotidiana. Asimismo, descubren la necesidad de actualizar la imagen de una "escuela exitosa" a la de una "escuela de calidad competitiva".

En el marco de la Reforma Educativa 2013, Pérez-Ruiz (2014) estudia los diferentes enfoques para analizar las nuevas formas de administración pública aplicadas a la educación, como parte de los procesos de Reforma Educativa que se han implementado en varios países latinoamericanos. En ese sentido, la idea de reorganizar las escuelas se inserta en un contexto de cambio que promueve la descentralización, pero que a la vez considera mecanismos más flexibles de operación. Rivero (2016) cuestiona si elevar la autonomía de gestión escolar a rango constitucional, al incorporarlo a la fracción III del artículo $3^{\circ}$ constitucional, así como todo el marco normativo y jurídico que lo acompaña, como lo son su inclusión en el artículo 22 y en el artículo 28bis de la Ley General de Educación, en los acuerdos 716 y 717 publicados en el Diario Oficial de la Federación, que regulan el funcionamiento de la misma y que contemplan órganos de gestión como los Consejos Escolares de Participación Social 
y los CTE, que deben seguir mecanismos e instrumentos como la Ruta de Mejora Escolar, en realidad dotan de autonomía de gestión a las escuelas o si se trata de una estructura altamente supervisada que mantiene en pie las limitantes a la misma.

A octubre de 2019, seguían vigentes los Lineamientos para la organización y el funcionamiento de los Consejos Técnicos Escolares (DOF, 2016) que los consideran el "espacio de análisis y toma de decisiones que propicia la transformación de las prácticas docentes y facilita que niños y adolescentes logren los aprendizajes esperados, de modo que la escuela cumpla con su misión.”. El Estado, a través de la Secretaría de Educación Pública (SEP), determina dichos lineamientos, así como las metas y los objetivos a cumplir, provenientes de la propia legislación y de las diversas acciones en materia de política educativa. Se trata de un órgano de gobierno que posibilita la autonomía de los centros educativos, primordial para concretar la política educativa. Sin embargo, hasta la publicación del Decreto por el que se reforman, adicionan y derogan diversas disposiciones de los artículos 3o., 31 y 73 de la Constitución Política de los Estados Unidos Mexicanos, en materia educativa (DOF, 2019a), la atención general se había centrado en la evaluación y profesionalización docente, el concepto de calidad, la idea de eficacia escolar, todos aspectos muy relevantes, pero, si quedan en el plano del discurso, pocos serán los verdaderos resultados. En la denominada Reforma Educativa 2019 se les incluyó, explícitamente, en su artículo Transitorio $17^{\circ}$ :

dentro de los consejos técnicos escolares, se integrará un Comité de Planeación y Evaluación para formular un programa de mejora continua que contemple, de manera integral, la infraestructura, el equipamiento, el avance de los planes y programas educativos, la formación y prácticas docentes, la carga administrativa, la asistencia de los educandos, el aprovechamiento académico, el desempeño de las autoridades educativas y los contextos socioculturales. Dichos programas tendrán un carácter multianual, definirán objetivos y metas, los cuales serán evaluados por el referido Comité.

En dicha mención, quedan asentadas, de manera explícita, sus funciones, orientadas a la autonomía de gestión escolar. 


\section{REVISIÓN DE LA LITERATURA}

Comprender los procesos de resignificación de reformas y políticas en el seno escolar también parte de un entendimiento de las prácticas sociales que se dan en el mismo. La revisión de la literatura sobre las prácticas sociales relacionadas con la autonomía de gestión escolar en el marco de los Consejos Escolares arroja que es un tema relativamente reciente. Debido a ello, se decidió no restringir la búsqueda a los documentos de los últimos años, sino hacer una búsqueda histórica para realizar ese rastreo. Los operadores que se trabajaron fueron "autonomía de gestión", "consejo escolar" $O R$ “consejo técnico escolar" OR "CT” OR "CTE”, y "educación básica”. Tras la primera búsqueda, se localizaron 84 textos relacionados con los términos de búsqueda, en su mayoría provenientes de Redalyc y Memorias COMIE, y en mucho menor medida, de JSTOR, Scopus, Web of Science y Academic Search Complete. Tras una primera depuración, se redujo la cantidad a 59 textos, de los cuales únicamente 40 se mantuvieron por ser documentos de índole científico, es decir, de corte empírico con fundamento teórico-metodológico.

En razón de ello, se recuperaron artículos en revistas arbitradas y ponencias en congresos nacionales. En su gran mayoría, se trata de investigaciones mexicanas sobre temas nacionales. Los estados estudiados son Baja California, Chihuahua, Ciudad de México, Coahuila, Estado de México, Jalisco, Nuevo León, Querétaro, Tamaulipas, Veracruz, Durango (dos casos) y Tlaxcala (tres casos). Se realizó una segunda búsqueda ampliando a otros idiomas, lo que arrojó otros 16 resultados. Entre esas experiencias internacionales destacan, por cantidad, los estudios de América (cuatro de Brasil, uno de Argentina y uno de Estados Unidos), seguidos por cuatro de Asia (dos de Indonesia, uno de Tailandia y otro más de Israel), tres de África (Zambia, Egipto y Etiopía), dos de Europa (España y Turquía) y uno más que realiza un comparativo internacional entre seis países (Australia, Canadá, Hong Kong, Nueva Zelanda, Reino Unido y Estados Unidos). Entre éstos, se mantuvieron diez en el análisis por ser resultados de investigación y por su relevancia temporal. 


\section{Rastreo histórico}

A escala internacional, el primer estudio identificado sobre autonomía de gestión escolar es el del estadounidense Keene (1980), en el cual se explica tal denominación como el cambio de la toma de decisiones de la autoridad central a la escuela y se analizan las consideraciones más importantes que habrían de tomarse en cuenta antes de establecer tal cambio de responsabilidades. Waxman (1985) plantea los beneficios de la autonomía de gestión escolar en la implementación de estrategias curriculares. Para 1990, Brocato advierte que en el marco de la reforma derivada del informe que el entonces presidente, Ronald Reagan, encargara a la National Commission on Excellence in Education, no se debe considerar la autonomía de gestión escolar como una panacea. Los estudios británicos de Crick (1998) y Hannan (1998) ya hacen mención de los consejos escolares como una entidad con efectos democratizantes. El libro de Abu-Duhou (1999) -el cual es el único documento que no es un artículo o ponencia- hace una revisión de las reformas y políticas en torno a la autonomía de gestión escolar de los 20 años previos en los países de habla inglesa, así como los efectos que éstas habían tenido para entonces.

La referencia más antigua que se identifica en América Latina es la de Ezpeleta (1990), multicitada en el resto de la literatura encontrada en idioma espańol, pero no se trata de un resultado de investigación empírica, sino que es un aporte teórico sobre la importancia de la dinámica institucional de las escuelas para el trabajo pedagógico. Asimismo, por su reiterada citación en las fuentes consultadas, se hizo la búsqueda específica al texto de Fierro y Rojo (1994), el cual es un libro disponible actualmente en línea, resultado de una investigación realizada en el estado de Guanajuato, pero cuyos resultados se plantean a manera de manual, por lo que carece de secciones de metodología, fundamentación teórica, conclusiones e incluso referencias bibliográficas.

No es sino hasta 2003 que se encuentran los primeros resultados de investigación empírica en Jiménez (2003), con su estudio sobre la reestructuración de la escuela y las nuevas pautas de regulación del trabajo docente, y en Tapia (2003) sobre el estado inicial de las escuelas primarias de educación indígena del Programa 
Escuelas de Calidad. Después se ubican cuatro textos entre 2006 y 2007 (Astiz, 2006, Robkob, 2006, Cruz, 2007, y Martínez y Vega, 2007) y, tras un lapso de cuatro años sin publicaciones al respecto, se vuelven a encontrar algunos artículos entre 2011 y 2015 (Tapia, 2011, del Castillo, 2012, Encinas y Mercado, 2012, Estrada, 2012, CEE, SIEME y HE, 2013, Ortiz, Viramontes y Guevara, 2015, Rubio, Castro y Félix, 2015) con un leve pico en 2014 (Arzola, 2014, de León e Infante, 2014, González, 2014, Sánchez y Corte, 2014, y Santibáñez, Abreu y O’Donoghue, 2014). Sin embargo, a partir de 2016 se da un repunte orientado, en su mayoría, a aspectos de gestión educativa (Ávila et al., 2016, Estrada y Sánchez, 2016, Flores y García, 2016, González y García, 2016, Landín y Sánchez, 2016, Martínez, 2016, Perales y Escobedo, 2016, y Weiss, 2016) que se dispara en 2017 con textos de la misma orientación, pero más enfocados a lo relativo a la autonomía (Carrasco, Carro y Hernández, 2017, Carro y Arroyo, 2017, Galván y Espinosa, 2017, González, de la Garza y de León, 2017, Martínez y Moreno, 2017, Mondragón, 2017, Ortega, 2017, Ortega y Hernández, 2017, Pérez-Ruiz, 2017, Rubio, 2017, Silas, 2017, Silva y Miranda, 2017, y Solís, Valenzuela y García-Poyato, 2017). Es importante destacar que la mayoría de éstos son avances de investigación presentados en el marco del XIV Congreso del COMIE. Para 2018, se percibe una fuerte baja, encontrándose únicamente el texto de Carro, Lima y Carrasco (2018) que además proviene de la misma investigación de base que el de Carrasco, Carro y Hernández (2017), e incluso llega a idénticas conclusiones.

Sólo Carrasco, Carro (Carrasco, Carro y Hernández, 2017, Carro, Lima y Carrasco, 2018, Carro y Arroyo, 2017), Ortega (Ortega, 2017, Ortega y Hernández, 2017) y Tapia $(2003,2011)$ tienen más de una publicación sobre el tema. El resto son autores que no han vuelto a atender el mismo (figura 1 ). 
FIGURA 1.

Progresión en la literatura sobre las prácticas sociales relacionadas

a la gestión escolar en el marco de los Consejos Escolares
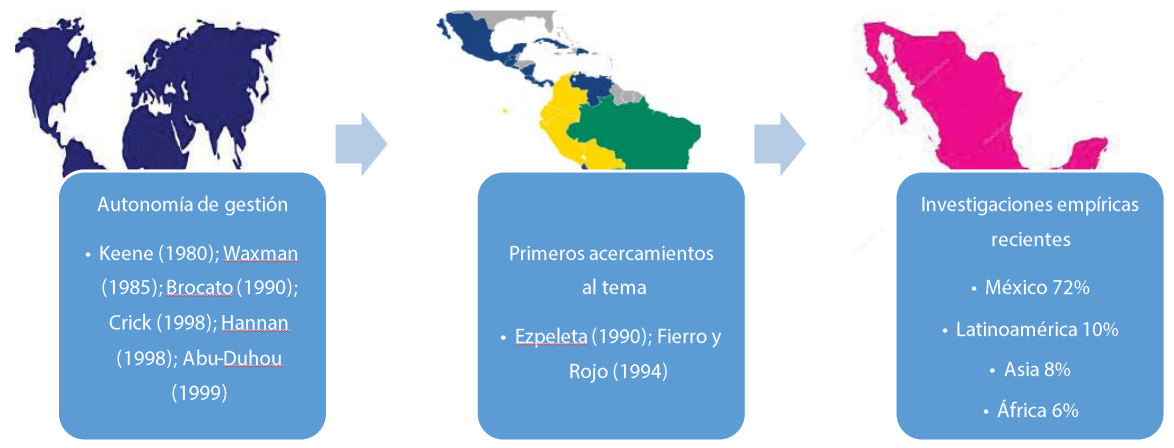

Fuente: elaboración propia.

\section{CAMPOS Y DIMENSIONES DE INDAGACIÓN}

Se identifican, principalmente, dos campos de indagación: la política educativa y la gestión educativa. En el primero, se pueden agrupar los textos en aquellos que se interesan en la adopción (Jiménez, 2003, Astiz, 2006, Arzola, 2014, y Weiss, 2016) e implementación de políticas (Martínez y Vega, 2007, Tapia, 2011, del Castillo, 2012, de León e Infante, 2014, Sánchez y Corte, 2014, Santibañez, Abreu y O’Donoghue, 2014, y Estrada y Sánchez, 2016), y los que atienden aspectos relacionados con la micropolítica escolar (Cruz, 2007, Encinas y Mercado, 2012, González, 2014, Mondragón, 2017, y Pérez-Ruiz, 2017).

En cuanto al segundo, se identifican, principalmente, los que se enfocan a la autonomía (Carrasco, Carro y Hernández, 2017, Carro, Lima y Carrasco, 2018, Ortega, 2017, Silas, 2017, Silva y Miranda, 2017, Solís, Valenzuela y García-Poyato, 2017) y organización escolar (Robkob, 2006, Landín y Sánchez, 2016, Perales y Escobedo, 2016, Carro y Arroyo, 2017, Estrada, 2012, Martínez y Moreno, 2017, y Rubio, 2017), la evaluación educativa (CEE, SIEME y HE, 2013), la inclusión educativa (Flores y García, 2016, Galván y Espinosa, 2017, y Ortega y Hernández, 2017) la intercul- 
turalidad (Tapia, 2003, González y García, 2016, y Martínez, 2016) y la formación docente (Ortiz, Viramontes y Guevara, 2015, Rubio, Castro y Félix, 2015, González, de la Garza y de León, 2017, y Ávila et al., 2016). En ambos casos, los conceptos que se encuentran más presentes son: gestión, trabajo colaborativo, educación básica, docentes, cultura escolar y reforma (figura 2).

- FIGURA 2.

Campos de indagación

\section{Política educativa}

GESTION
DEMOCRATICA

Fuente: elaboración propia

Las dimensiones prioritarias, en todos los casos, son psicológica, social, política, pedagógica, organizacional y profesional. Las evidencias empíricas de las que parten estas dimensiones son las siguientes.

\section{Dimensión psicológica}

Desde lo psicológico, se toman en cuenta las relaciones interpersonales, los comentarios de los docentes y alumnos, las representaciones sociales que expresan los docentes acerca del trabajo colaborativo y los sentidos y representaciones que tiene la comunidad educativa de la política de participación social.

\section{Dimensión social}

Desde la dimensión social, se considera el involucramiento de los maestros en la toma de decisiones; las posturas auto, hetero e interformativas de los docentes, las prácticas de colaboración docente; la 
correlación entre los niveles de participación de los docentes en el programa CM y el aprovechamiento escolar de sus alumnos en las asignaturas de español y matemáticas; los elementos fundamentales que apoyan los procesos sistemáticos de cambio y mejora institucional; la red social, conformada por sujetos y organismos de la educación básica regional; las actividades que se realizan en los Consejos Escolares, y las dinámicas que se generan en las academias y en los órganos diseñados para la participación social en la educación.

\section{Dimensión política y dimensión organizacional}

Desde la dimensión política, se parte de la capacidad de intervención gubernamental a la luz de la resolución de problemas pendientes en la agenda de las políticas; el contexto familiar y social de las comunidades indígenas; la corresponsabilidad entre los actores educativos, y los procesos sociopolíticos que atraviesan la escuela. Desde la dimensión organizacional se hace referencia a la construcción y ejecución del proyecto escolar, así como al cumplimiento de objetivos y ejercicio de atribuciones en los Consejos Escolares.

Se identifica una suerte de conjunción entre las dimensiones política y organizacional al tomar en cuenta evidencia empírica que tiene que ver con el control y el conflicto, como las horas cocurriculares que los maestros desempeñan fuera de horario de clases; el funcionamiento y las reuniones de los CTE; las presiones ejercidas por los exámenes estandarizados a que son sometidos los alumnos y los maestros; las actividades administrativas que se exigen a los maestros en su quehacer cotidiano; los ejes de la gestión escolar en documentos oficiales; los procesos de capacitación que imponen inversión de tiempo fuera de las actividades del profesor; las líneas oficiales sobre los modelos de gestión que acompañan cada etapa reformista, poniendo especial énfasis en el rastreo del surgimiento y funcionamiento de los CTE, convirtiéndolo en un espacio para el control en la presente reforma; los mecanismos que ha seguido la política educativa en las últimas décadas; las estrategias para promover una nueva gestión escolar; la relación entre los apoyos que, teóricamente, debe recibir el estudiantado con discapacidad y los que realmente recibe para garantizar su inclusión, funciones del Consejo Técni- 
co y los rasgos característicos de las escuelas eficaces; los procesos de aculturación que afectan a las familias y a la comunidad otomí en general; las políticas públicas educativas; los programas y planes relacionados con la sustentabilidad, y los estándares curriculares, estándares de desempeño docente y estándares de gestión escolar.

\section{Dimensión pedagógica}

Desde la dimensión pedagógica, se enfatiza sobre todo en aspectos relacionados con la práctica educativa, como prácticas pedagógicas; el uso de la lengua indígena; las prácticas de evaluación de aprendizajes a partir del trabajo colaborativo; situaciones y eventos en el aula; la diversidad en un grupo multigrado y sus implicaciones para la enseñanza; la intervención pedagógica; el diagnóstico situacional con los actores de los diferentes niveles y modalidades que comprende la educación básica (primaria y secundaria) en los ámbitos de calidad educativa, inclusión y equidad; los momentos específicos de clase para incitar a la reflexión sobre el logro de un objetivo de innovación, y datos cualitativos sobre distritos escolares

\section{Dimensión profesional}

Desde la dimensión profesional, destacan aspectos que tienen que ver con la práctica y trayectoria docente, como las experiencias de observación de la práctica docente; el liderazgo en el quehacer pedagógico y la función directiva. La formación se observa desde ambas dimensiones, la pedagógica y la profesional, con un único caso en que se consideran los principales aprendizajes que han obtenido los docentes de educación básica al trabajar en Consejo Técnico Escolar para potenciar una efectiva gestión educativa (figura 3). 
Figura 3.

Dimensiones de indagación



Fuente: elaboración propia.

\section{ENFOQUES METODOLÓGICOS}

Por otro lado, las evidencias metodológicas surgieron, principalmente, a partir de enfoques cualitativos. De los 38 documentos, únicamente ocho son de corte cuantitativo (Tapia, 2003 y 2011, Robkob, 2006, Martínez y Vega, 2007, Ortiz, Viramontes y Guevara, 2015, Carrasco, Carro y Hernández, 2017, Ortega y Hernández, 2017, y Solís, Valenzuela y García-Poyato, 2017) y dos son mixtos (CEE, SIEME y HE, 2013, y Estrada, 2012). Se privilegia el uso de entrevistas, análisis documentales, cuestionarios y observaciones. En menor medida, también se recurrió a las historias de vida, la videograbación y las representaciones sociales. Fue muy escaso el uso de estadísticas, grupos focales, así como el uso de metodologías alternativas como la introspección histórica, la metodología APRA 
(Acceso, Permanencia y Rendimiento Académico) y el modelo de gestión democrática (gráfica 1).

- Gráfica 1

Enfoques metodológicos



Cualitativo $\square$ Cuantitativo $\square$ Mixto

Fuente: elaboración propia.

La población de estudio es predominantemente la de los docentes (30 casos), seguidos de directivos (18 casos), alumnos (8 casos), familiares ( 6 casos), administradores ( 5 casos), autoridades ( 4 casos) y supervisores (4 casos) (gráfica 2).

Entre los 28 textos cualitativos, las categorías se sistematizaron para identificar las siguientes categorías genéricas: dentro de la dimensión psicológica, la inseguridad, la intersubjetividad y la resignificación; dentro de la dimensión social, las expresiones de cambio y las de resistencia; dentro de la dimensión política, el control, los intereses, el conflicto y los ciclos de políticas; dentro de la dimensión pedagógica, la formación y las prácticas educativas; en la dimensión organizacional, la cooperación, el control y el conflicto, y en la dimensión profesional, la formación, la práctica y la trayectoria (figura 4). 
- Gráfica 2.

Incidencia de poblaciones estudiadas



Fuente: elaboración propia.

\section{PROBLEMAS INVESTIGADOS}

Los problemas que se han investigado se dividen, a continuación, a partir del campo de estudio y de las dimensiones que atienden.

\section{Política educativa: adopción, implementación y micropolítica}

Desde política educativa, la literatura se enfoca en la adopción de políticas, en la implementación de las mismas y en la micropolítica. En este punto es importante subrayar que la diferencia entre adopción e implementación de políticas parte de la dirección en que se da el proceso. En el caso de la adopción, se parte del nivel micro, es decir, la manera en que los actores educativos acogen las líneas de política; mientras que en el de la implementación, lo hace del macro, es decir, la forma en que las autoridades aplican esas mismas líneas. Asimismo, habrá que mencionar que la noción de micropolítica en el presente documento parte del análisis de la micropolítica 
de Ball (1994), que analiza las tensiones y articulaciones que se dan entre los actores, los intereses y conflictos en juego, así como las vías que cada parte sigue para alcanzar sus objetivos y las brechas que ello genera entre una reforma o política y su implementación en las escuelas.

- Figura 4.

Categorías cualitativas
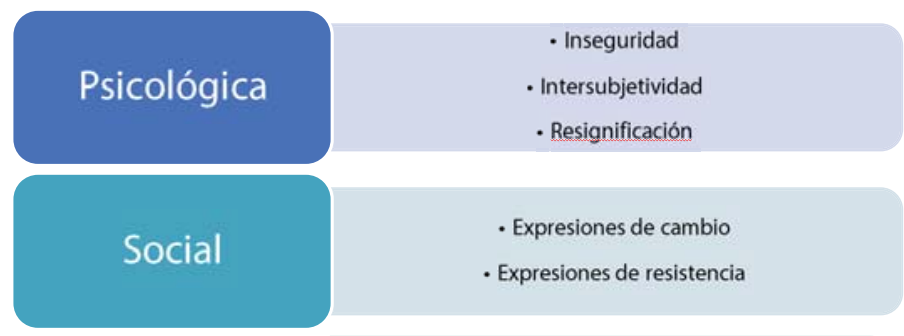

- Expresiones de cambio

- Expresiones de resistencia

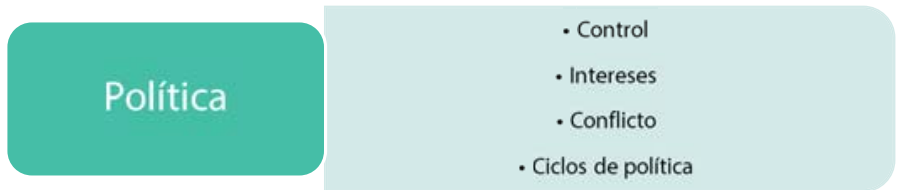

Pedagógica

- Formación

- Práctica educativa

\section{Profesional}

- Formación

- Práctica

- Trayectoria

Fuente: elaboración propia.

En cuanto a la adopción de políticas, Arzola (2014) se interesa en los elementos que giran en torno a los intentos por establecer mecanismos de participación y colegialidad en escuelas secundarias federalizadas del estado de Chihuahua. Astiz (2006) estudia los resultados y las consecuencias de la autonomía escolar en distritos 
escolares de Buenos Aires, Argentina. Jiménez (2003) analiza la reestructuración del trabajo docente durante la transición de una organización basada en la estructura burocrática hacia otra basada en mecanismos de autocontrol y en la individualización de los reconocimientos e incentivos para los maestros como trabajadores. Por su lado, Weiss (2016) se enfoca en las dos configuraciones del tutor y de la tutoría y sus orígenes en dos tradiciones escolares: la del asesor de grupo y la del orientador educativo. En el ámbito internacional, Hammad (2013) destaca la aparente paradoja entre las exigencias provenientes de la política de autonomía de gestión escolar en Egipto y las prácticas reales en los centros escolares. En todos estos casos es evidente la tensión que se genera ante los cambios que desencadenan las reorientaciones en la política educativa.

Los textos que se refieren a la implementación de políticas son, a su vez, una suerte de recuento de los distintos momentos de cambio a los que se ha sometido el colectivo escolar y de las diferentes políticas que han estado en boga. Martínez y Vega (2007) analizan la manera como se evalúan los factores que contempla la primera vertiente del programa de Carrera Magisterial, la incorporación o promoción de los maestros que se encuentran frente a grupo. Tapia (2011) estudia la forma en que se articulan la "gestión educativa" y la "práctica escolar" en la construcción del proyecto de enseñanza vivencial de las ciencias, en cuanto a las reglas de participación de maestros, directivos, padres de familia, consejos técnicos escolares, y mandos medios. Del Castillo (2012) aborda la implementación de políticas desde la experiencia de las reformas de las políticas educativas en México de los últimos veinte años, mientras que Sánchez y Corte (2014) identifican los rasgos que caracterizan la práctica docente del profesor de español en las últimas décadas. Por otra parte, De León e Infante (2014) analizan la manera en que la sustentabilidad se ubica dentro de las políticas educativas, y Estrada y Sánchez (2016) atienden las representaciones que imperan sobre la participación social en la educación en los distintos consejos en los que ésta se desarrolla formalmente. Desde la experiencia internacional, Leer (2016) realiza una estimación de los efectos de las políticas de descentralización en los resultados educativos en Indonesia, mientras que Okitsu y Edwards (2017) revisan si las reformas orientadas 
a la autonomía de gestión en Zambia han logrado implementarse, tal como lo preveía el discurso político, contrastándolo con los significados locales de la participación de la comunidad en la gestión escolar.

En el ámbito de la micropolítica, Cruz (2007) aborda el sentido y el significado de las expresiones de ritualidad que adoptan los maestros y el director a través de sus diversas representaciones, ideas y creencias en torno a las actividades regulares que realizan en las reuniones de Consejo Técnico Escolar, el conjunto espacio-tiempo donde toman decisiones que influyen en la trama organizativa del plantel. Encinas y Mercado (2012) estudian los procesos cotidianos que posibilitan la conformación de colectivos docentes en la escuela; mientras que González (2014) lo hace con las representaciones sociales que expresan los docentes del trabajo colaborativo a partir de sus dimensiones. Mondragón (2017) analiza el modelo de gestión que acompaña a la actual política educativa en México, específicamente, desde las diversas formas en que los directores de educación secundaria han asumido la consigna de ser garantes de la mejora de los centros escolares a través de la coordinación del trabajo de los CTE, y Pérez-Ruiz (2017) las atribuciones de sentido por parte de los maestros frente al imperativo de mejorar su práctica y tener una mayor participación en la toma de decisiones.

Es muy importante señalar que ninguno de los textos recuperados analiza la puesta en acto de las reformas y políticas educativas. Por supuesto, de ninguna manera esto implica que no existan documentos especializados en estudiar la puesta en acto de reformas y políticas educativas; existen bastantes tanto en el contexto internacional como en el latinoamericano. Sin embargo, dada la importancia de este concepto en el ámbito de la micropolítica, es sobresaliente que las investigaciones interesadas en esta problemática no lo hayan abordado. La puesta en acto va más allá de la adopción de una política, incluye expresiones de cambio y de resistencia a la misma que dependen de la subjetividad de los actores (Ball et al., 2017). En este sentido, las investigaciones que enfatizan lo micro-institucional, por lo general destacan la fuerza que desde el seno escolar se gesta como determinante para la puesta en acto de las nuevas políticas. 


\section{Gestión educativa: los ámbitos de alcance de la organización escolar}

Desde el campo de la gestión educativa, la revisión de la literatura permite identificar investigaciones orientadas a la problemática en torno a la autonomía, la organización escolar, la formación, la inclusión, la interculturalidad y la evaluación, en ese orden de relevancia.

En relación con la autonomía, Carrasco, Carro y Hernández (2017) identifican las prioridades y condiciones educativas que el personal directivo de las escuelas está implementado para fortalecer la autonomía de gestión en las escuelas de educación básica del estado de Tlaxcala. Carro, Lima y Carrasco (2018) estudian las estrategias que se están implementando en las escuelas para fortalecer la autonomía de gestión en cuatro prioridades definidas en la ruta de mejora y en el Plan Nacional de Desarrollo 2013-2018. Cuatro estudios vinculan directamente al CTE con los procesos de autonomía: Ortega (2017) identifica los principales aprendizajes que han adquirido los docentes dentro de este órgano para potenciar los procesos de gestión que se viven dentro de las escuelas y, con ello, favorecer la calidad educativa en México; Silas (2017) analiza la manera en que se da la autonomía de gestión en el CTE; Solís, Valenzuela y García-Poyato (2017), la perspectiva que tienen distintos actores ante el funcionamiento de los CTE y cómo se definieron esos problemas.

Desde el ámbito latinoamericano, Silva y Miranda (2017) investigan sobre los factores que promueven o dificultan la participación del Consejo Escolar en las decisiones de educación básica de las escuelas de un municipio brasileño. De esta manera, en estos estudios queda claro, por un lado, la prevalencia que ha adquirido el tema del fortalecimiento de la autonomía de gestión escolar y, por otro, el papel fundamental que desempeña el CTE en ese proceso. Las experiencias internacionales revelan una orientación interesante distinta del resto. Se trata de la gestión democratizante, presente en los estudios de Güven, Çam y Sever (2013), Marques (2012), Mitchell (2017) y Montero (2010). En éstos se aborda el tema de la autonomía de gestión como un motor hacia procesos de toma de decisión compartidos con la comunidad escolar extendida, es decir, no solamente el colectivo docente y el directivo, sino incluyendo a los alumnos e incluso a los padres de familia. 
Sobre la organización escolar, todos los textos la vinculan de manera directa ya sea con los colectivos docentes, ya con los consejos escolares. Martínez y Moreno (2017) revisan las representaciones que imperan sobre la participación social en la educación en los distintos consejos en los que ésta se desarrolla formalmente; Landín y Sánchez (2016) estudian la integración de un grupo de profesores para generar un trabajo colegiado que promoviera la reflexión y el aprendizaje sobre la experiencia docente a través de la narrativa educativa. Carro y Arroyo (2017) identifican los alcances y las limitaciones existentes a cuatro años de ser instituido el CTE como instancia de mejora. Estrada (2012) busca definir una tipología generalizada a través del funcionamiento del CTE para develar una posible relación entre esa tipología y la eficacia escolar. Rubio (2017), por su parte, analiza las percepciones y funcionamiento de los CTE colocando en el foco las relaciones con la profesionalización docente y su impacto social y educativo. En el ámbito internacional, Robkob (2006) estudia el nivel de eficiencia de gestión escolar de instituciones de educación básica en Tailandia, de acuerdo con su tamaño y ubicación, para identificar procesos de mejora en esa área. Bandur (2012) se enfoca en los procesos de toma de decisiones participativos y de asociación en el nivel escolar; Ferreira, Corrochano y Leite (2018) analizan la relación entre escuela y comunidad a partir de los consejos escolares; mientras que Gaziel (2008) considera los efectos de las políticas de autonomía de gestión escolar sobre las actitudes de los maestros y sobre el logro de los estudiantes.

La formación docente también se considera un elemento de gestión. Ortiz, Viramontes y Guevara (2015) estudian la mejora de la enseñanza en el campo formativo de lenguaje y comunicación en jardines de nińos. Rubio, Castro y Félix (2015) revisan experiencias formativas significativas de futuros profesores de educación primaria en su trayecto académico en la escuela normal, y los retos que representa su ingreso al ejercicio profesional a partir de sus procesos de formación reciente. Ávila, et al. (2016) se orientan hacia el acompańamiento mediante un programa que atienda a un sector vulnerable de la población y que permite el diálogo entre autoridades, docentes e investigadores. Asimismo, González, de la Garza y de León (2017) identifican la manera en que los participantes del CTE analizan y evalúan su práctica docente y se plantean acciones de mejora. 
La inclusión se percibe como parte de los procesos de gestión escolar en las investigaciones encontradas. Flores y García (2016) estudian la coincidencia entre los apoyos que teóricamente deben otorgársele a la población estudiantil con discapacidad y los que realmente recibe, en el nivel de secundaria; Galván y Espinosa (2017), las prácticas docentes innovadoras para crear un repositorio del conocimiento profesional que se genera en situación multigrado, y Ortega y Hernández (2017) el nivel de implicaciones del género respecto a la eficacia en el funcionamiento de los Consejos Técnicos Escolares.

Del mismo modo, la interculturalidad se concibe como un aspecto que ha de gestionarse desde la escuela. González y García (2016) identifican los valores culturales que aún tienen las comunidades otomíes, como motor de un proyecto de educación intercultural para la promoción de la paz y la convivencia escolar; Martínez (2016) devela las relaciones culturales violentas de los alumnos ligados a grupos de poder y las respuestas de los docentes frente a ello, con la finalidad de contribuir a una propuesta basada en la interculturalidad, y Tapia (2003) analiza la situación inicial de las escuelas interculturales bilingües que participan en el Programa de Escuelas de Calidad.

La evaluación como proceso de gestión se analiza en CEE, SIEME y HE (2013), instituciones que revisan el rumbo del sistema educativo y el nivel de la calidad de la educación básica en México.

\section{PRINCIPALES PRODUCTOS \\ DE INVESTIGACIÓN EN LA LITERATURA}

\section{EI CTE en la adopción e implementación de políticas}

Desde la adopción de políticas, Jiménez (2003) advierte que, si bien la descentralización reconocía las necesidades locales, devolvía las responsabilidades sociales y promovía la transformación de la escuela desde ella y sus comunidades a través de propuestas como el fortalecimiento de los CTE y la formulación de un proyecto escolar, en la práctica eso se tradujo en formalismos técnicos y en una ejecución de "efímero impacto" tanto en lo local como en lo inmediato. 
Arzola (2014) identifica una desarticulación entre la cultura escolar y la conceptualización política de trabajo colegiado y de participación. Los organismos de gestión y participación como el CTE y los Consejos Escolares de Participación Social se encuentran poco definidos en la idiosincrasia escolar, por lo que suelen confundirse con otras instancias como las academias o adquieren atribuciones que no les corresponden o que son, incluso, antagónicas a sus objetivos de creación, convirtiéndose en una "especie de tribunal que juzga a quienes infringen el orden establecido" (Arzola, 2014, p. 26). Weiss (2016) destaca que el alto grado de aceptación entre estudiantes, docentes y directivos de una línea de política como la implementación de tutorías, acompañada de una clara delimitación de las funciones de sus actores -en este caso, el tutor- y del tiempo reglamentario para su aplicación, que conlleva a resultados que mejoran el potencial pedagógico.

Desde la experiencia argentina, Astiz (2006) expone un caso de éxito en el que la eficiencia de la administración municipal llevó a una red de colaboración relativamente exitosa entre el consejo escolar local, el gobierno municipal, las unidades de supervisión, las escuelas y las organizaciones locales. Lo señala como una posibilidad para revitalizar la educación que apoya la articulación entre los requerimientos educativos y las ineficiencias administrativas locales. Asimismo, subraya que los estudios sobre autonomía escolar en América Latina no han atendido el papel que juegan "los factores organizacionales y los ambientes sociopolíticos en la implementación de esfuerzos de reforma y cómo esos factores contribuyen a explicar los resultados de las reformas". (Astiz, 2006, p. 204) Desde el continente africano, Hammad (2013) revela que la retórica que rodea el movimiento de autonomía de gestión escolar es, en realidad, más significativa que su sustancia, por lo que la experiencia en Egipto ha sido una paradoja entre política y práctica.

Sobre la implementación de políticas, Martínez y Vega (2007) puntualizan que el resultado más evidente del involucramiento del CTE como implementador de la evaluación en el programa de Carrera Magisterial fue prolongar la jornada de trabajo e intensificarle, lo cual estaba, además, vinculado al propio puntaje que recibían los maestros, como horas co-curriculares, fuera de clase. Tapia (2011, 
p. 253) identifica que la participación de los maestros a través CTE parece ser el mejor escenario para enfrentar los diversos retos que ha enfrentado el PVEC, como un medio ideal de "implementación de nuevas formas de aprendizaje de las ciencias mediante experiencias directas colectivas". Asimismo, destaca la importancia de la figura del director como tomador de decisiones, al implementar el programa y orientarse más a los asuntos pedagógicos que, tradicionalmente, se han desatendido en las reuniones colegiadas. Del Castillo (2012) señala que, para que el PETE se implemente de manera efectiva como instrumento clave de la política de gestión escolar, se debe avanzar hacia la profesionalización de los distintos actores que participan en su diseño, implementación y evaluación, así como lograr un mayor involucramiento de los órganos colegiados de las escuelas (Consejo Técnico Escolar) y de las zonas escolares (Consejo Técnico de Zona) en torno a la planeación estratégica. Al respecto, advierte que los CTE registran fallas importantes como no abordar temas centrales para la mejora educativa, sino saturar su agenda con temas técnico-administrativos.

Por otro lado, De León e Infante (2014) demuestran que el funcionamiento adecuado del CTE apoya la implementación exitosa de programas tan relevantes como el de Escuela Segura, Saludable y Sustentable de la Secretaría de Educación de Nuevo León, en coordinación con el resto de la comunidad escolar, padres y alumnos, por medio de comités y subcomités encargados de realizar el diagnóstico, la planeación y la evaluación del programa. Estrada y Sánchez (2016) destacan tres aspectos: la formalidad operativa de los consejos escolares en todos sus niveles, enfocados a la organización, la administración y la gestión; su representación como espacio de participación de los actores educativos, y el hecho de ser un apoyo formal, lo cual recupera como "una línea de entrada clara hacia la modificación o superación de la mera formalidad bajo la cual están representados los consejos escolares”. En Indonesia, Leer (2016) no encuentra ningún efecto general de las políticas de descentralización en el rendimiento de los estudiantes, pero sí un efecto negativo en el esfuerzo de los docentes, en especial en áreas rurales y entre escuelas con comités escolares inactivos. Del mismo modo, para Okitsu y Edwards (2017), la experiencia en Zambia 
destaca los problemas que enfrentan los maestros ante las demandas locales, en especial por los recursos, tan poco adecuados, que les proporciona el Estado.

\section{El CTE en la micropolítica escolar}

En el ámbito de la micropolítica escolar, los Consejos Escolares se descubren como espacio y tiempo centrales. Cruz (2007) destaca la influencia que tienen las costumbres, los hábitos, las tradiciones y los mitos en el desarrollo de una cultura académica en el seno del CTE, a lo que le denomina "el poder del ritual". Asimismo, puntualiza la relevancia de la eficacia simbólica de la junta de CTE, en especial en el momento de ritualización más fuerte, que identifica como la presentación de resultados de acciones educativas mediante las calificaciones de los alumnos. Ello lo lleva a plantear la necesidad de cuestionar estas prácticas de racionalidad cuantitativa y sus consecuencias en el plano pedagógico. Encinas y Mercado (2012) revelan que los docentes de su caso de estudio recurrieron a reuniones "fuera de la norma" para tratar sobre actividades educativas relevantes para su área, ya que las de CTE se limitaban a cuestiones administrativas. "Así, los profesores y otros protagonistas de la vida escolar sostenían constantes negociaciones de significado en cuanto a las implicaciones que, desde su perspectiva, tendría el trabajo de los colectivos para la escuela, o para las funciones académicas que desempeñaban, lo que daba lugar a procesos de micropolítica" (Encinas y Mercado, 2012, p. 209).

Asimismo, identifican que los CTE se han constituido en ámbitos de negociación entre autoridades y docentes y que, si las propias políticas educativas no los valoran como un espacio idóneo para el trabajo pedagógico, su práctica como tales se obstaculiza. Para González (2014), el CTE se revela como un órgano que favorece una sana interacción entre los maestros, pasando del individualismo al bien común mediante el trabajo colaborativo. Mondragón (2017) expone que el trabajo de los directivos se ha encasillado en actividades administrativas y que el caso de las reuniones de CTE no fue la excepción. Atribuye a la figura del director la labor de reorientar el trabajo colegiado hacia una verdadera integración y participación, 
en lugar de a la simulación, e incluso manipulación que permean y que han sepultado las funciones de autonomía de los Consejos Escolares. Esa simulación también queda descubierta en Pérez-Ruiz (2017, p. 64) quien destaca la sensación de simulación y desconfianza en torno a la vida colegiada, así como un manifiesto "malestar por la inconsistencia de los acuerdos y la poca claridad de sus implicaciones prácticas".

\section{EI CTE y la autonomía de gestión}

Desde el ámbito de la autonomía de gestión, Carrasco, Carro y Hernández (2017) y Carro, Lima y Carrasco (2018) identifican que los indicadores de mejora de autonomía de gestión escolar en las primarias de Tlaxcala han tenido un avance desigual. Ortega (2017) recupera que, al trabajar en sus procesos de autonomía en el marco del CTE, los docentes expresan que su mayor aprendizaje ha sido trabajar en equipo y compartir sus experiencias, aunque la carga administrativa se ha incrementado a pesar de que la SEP afirme lo contrario. Asimismo, Silas (2017) señala que la autonomía en el CTE de su estudio da visos de su existencia, pero que el trabajo real hacia las necesidades del centro educativo y hacia una coordinación interna ha sido obstaculizado por los lineamientos oficiales. "Las premisas de autonomía de gestión se ven limitadas precisamente por la misma estructura que debe fomentarlas y por la cantidad de acciones (y reportes) que involucra la autonomía” (Silas, 2017, p. 8). También Silva y Miranda (2017) acusan la burocratización de los Consejos Escolares, que afecta su existencia como mecanismo de democratización y de representatividad de una participación colectiva y autónoma real. Sin embargo, en el caso de Solís, Valenzuela y García-Poyato (2017) se encuentra que los participantes en el estudio consideran que los objetivos y las funciones del CTE se alinean a sus actividades adecuadamente.

Los hallazgos de las investigaciones internacionales en este ámbito se enfocan en la gestión democratizante. Montero (2010), en Espańa, y Marques (2012), en Brasil, llegan a la conclusión de lo esencial que es el órgano del consejo escolar para apoyar la toma de decisiones democrática, en específico, en la asignación de puestos 
directivos. En Turquía, Güven, Çam y Sever (2013) descubren que, a pesar de que tanto los profesores en servicio como aquéllos en formación tienen percepciones positivas en torno a los proyectos de gestión democrática, se enfrentan al problema de tener poco conocimiento sobre el mismo, por lo que asignan poca importancia a algunos factores. Finalmente, Mitchell (2017) encuentra que, en Etiopía, los foros consultivos y de toma de decisiones permiten a la comunidad escolar compartir puntos de vista sobre la conducta dentro de la comunidad escolar, lo que cumple una importante función de responsabilidad.

\section{EI CTE y la organización escolar}

En cuanto a la organización escolar, Estrada (2012) encuentra que, a mayor peso de la función académica del CTE, se encuentran más características asociadas a las escuelas eficaces. Landín y Sánchez (2016) recomiendan que se creen espacios colectivos para reflexionar sobre el trabajo en aula como un acompañamiento para los docentes que redunde en la mejora de sus prácticas. Carro y Arroyo (2017) revelan que prevalece un comportamiento individual entre el colectivo, así como la burocratización de procesos y la falta de otros procesos metodológicos y pedagógicos que se relacionen con la planeación escolar y el liderazgo. Asimismo, que falta "consolidar procesos de formación para un diálogo de saberes pedagógicos que permitan un involucramiento profesional para la mejora educativa." (Carro y Arroyo, 2017, p. 11). Martínez y Moreno (2017) afirman que hay dos funciones centrales del CTE, ser una instancia de apoyo formal en cuanto a organización, administración y gestión, y ser un espacio de participación. Robkob (2006) ofrece algunas medidas para mejorar la eficacia de la gestión escolar mediante su buena organización: involucrar a todos los participantes, consolidar equipos de trabajo y establecer redes administrativas para apoyar la gestión financiera. Rubio (2017) señala que existe una incongruencia entre el discurso político y el administrativo, tendiendo uno a lo organizacional y el otro a distraer al docente con tareas burocráticas. Asimismo, existe una incongruencia entre quien encabeza las reuniones de CTE y su falta de autoridad, y una más entre el compromiso que se requiere de 
los profesores y aquellos que lo ven como un espacio de relajación. Todas estas incongruencias culminan en indiferencia y mediocridad. El estudio de Gaziel (2008) arroja que la autonomía de gestión escolar en su aspecto administrativo no mejora la satisfacción laboral, el agotamiento de los maestros ni el rendimiento de los estudiantes. Bandur (2012) descubre que la autonomía de gestión escolar ha creado procesos de toma de decisiones participativos y de asociación en el nivel escolar. El trabajo de Ferreira, Corrochano y Leite (2018) revela nuevas formas de cooperación escuela-comunidad

\section{La formación docente en el CTE}

Sobre formación docente, Ávila et al. (2016) acusan que ni los CTE ni el servicio de asesores técnico-pedagógicos han cambiado la tendencia de un sistema educativo centralizado que pretende formar a los docentes como reproductores de currículos o de modelos preestablecido desde arriba. Ortiz, Viramontes y Guevara (2015) exponen que, ante diversas opciones de formación docente, el CTE se ha considerado un programa predominante de formación continua, ya que funciona como un espacio de reflexión conjunta sobre las necesidades personales y las áreas de oportunidad específicas. Sin embargo, advierten que los resultados demuestran que no ha sido suficiente para alcanzar la meta esperada. Asimismo, Rubio, Castro y Félix (2015) identifican el trabajo colegiado como uno de los espacios con mayor impacto en la formación de docentes de reciente ingreso, ya que se involucran de principio a fin en lo que implica la labor docente. En el mismo sentido, González, de la Garza y De León Hernández (2017) afirman que el trabajo colaborativo en el marco de los CTE los ha fortalecido como espacios para la formación continua, dado el intercambio de experiencias y los elementos teóricos que apoyan un mejor entendimiento de la práctica cotidiana.

\section{Manejo de inclusión desde el CTE}

Sobre la inclusión, Flores y García (2016) señalan la relevancia de la participación del personal de educación especial en el CTE, dado que es donde los docentes expresan sus necesidades y donde les pue- 
den colaborar con sus sugerencias, pero que existe una falta de trabajo colaborativo al diseñar el plan anual de trabajo de la escuela. Galván y Espinosa (2017) advierten que la atención a la diversidad va más allá de la organización escolar y que es un proceso muy complejo que varía de acuerdo con las circunstancias particulares de cada escuela. Ortega y Hernández (2017) determinan que, si bien no hay implicaciones de género significativas en el funcionamiento de los CTE, las percepciones entre los hombres y las mujeres que participan en él sí muestran diferencias.

\section{Trabajo de interculturalidad en el CTE}

En lo que respecta a la interculturalidad, González y García (2016) expresan que parte de las prácticas dentro del propio centro educativo, entre profesores, entre estudiantes y más allá en la comunidad educativa, entre padres de familia. Martínez (2016) resalta la intensa participación del personal en el CTE al tratar sobre la prioridad relativa a la convivencia escolar sana, pacífica y formativa, pero que, al transmitir los conflictos del aula a las reuniones de CTE, se fragmenta la articulación pedagógica desde la estructura organizacional, por lo que las medidas de atención no siempre responden a intereses y necesidades personales de los alumnos. Tapia (2003) expone que, a partir de las reuniones de CTE y del proyecto escolar resultante, se observan cambios en la manera como se desenvuelven los niños tanto en su lengua indígena como en español, así como un mayor interés de éstos por aprender y una mayor preocupación de los maestros por el aprendizaje de los niños. Sin embargo, reconoce que en las comunidades rurales hay escuelas que carecen de CTE y, por tanto, de un plan anual de trabajo colectivo, por lo que cada maestro, en solitario, debe hacerse cargo de sus propias estrategias pedagógicas. Destaca que la participación de todos en los Consejos Escolares parece ser la clave para impulsar la autonomía de gestión de las escuelas.

\section{EI CTE y la evaluación}

Por otro lado, la evaluación como medida de eficacia en la gestión escolar revela, en el caso de CEE, SIEME y HE (2013), que la par- 
ticipación de los padres, tanto en el hogar, en la escuela y en el CEPS, tiene una relación negativa con el rendimiento académico. Las instituciones que firman el documento advierten, sin embargo, que tal resultado requiere de mayores estudios, ya que contradicen la teoría que asocia estos factores con las buenas prácticas de gestión. Asimismo, identifican al CTE, junto los supervisores y la reducción de carga administrativa, como tres aciertos de la política pública que pueden contribuir a fortalecer los centros escolares del país.

\section{ORIENTACIONES AL FUTURO}

La revisión de la literatura sobre las prácticas sociales relacionadas con la autonomía de gestión escolar en torno a los Consejos Escolares vincula la gestión escolar como un aspecto central de la micropolítica escolar que, a su vez, se articula con la política educativa a nivel macroinstitucional. Esta confluencia no sólo sustenta el marco teórico de la investigación marco, sino que abre interesantes líneas de indagación para la misma y que derivan de las preguntas de investigación, como hasta dónde los Consejos Escolares se apropian eficazmente de esa autonomía de gestión escolar en su resignificación de reformas y políticas.

Sin embargo, en las investigaciones encontradas se detecta que no existen análisis de micropolítica enfocados en el proceso de la puesta en acto de las reformas o políticas. Ello es de vital importancia pues, como ya se mencionó, la puesta en acto considera fuerzas, interacciones y especificidades con un abordaje distinto de los estudios sobre adopción o implementación de políticas. El análisis de la puesta en acto hace patente que en ese proceso de resignificación están involucradas muchas fuerzas, tanto desde el nivel macro como el del micro, que a partir del marco teórico se identifican como el control, los intereses y el conflicto. Asimismo, las dimensiones identificadas en la literatura se abordan de manera independiente, pero para la investigación marco y otras similares es primordial identificar cómo se relacionan la micropolítica, la organización y la autonomía escolar, como aspectos que se vinculan al proceso de la puesta en acto de políticas. 
A la luz de esto, es de primordial trascendencia analizar los significados que construyen los actores de la micropolítica en las escuelas públicas estudiadas al poner en acto las políticas y reformas en torno a la autonomía de gestión escolar en el espacio de los Consejos Escolares, en especial, a partir del entendimiento de las dinámicas entre las fuerzas involucradas en ambos niveles. Para ello habrá, asimismo, que definir las prácticas sociales resultantes del Consejo Escolar, esbozar a nivel de la micropolítica cómo se recrean las reformas y políticas en torno a la autonomía de gestión escolar en ese espacio y cómo se permean aquéllas orientadas a la calidad y equidad educativas.

Como problema de investigación, se espera que la investigación marco aporte al conocimiento de la relación entre política y gestión educativa visto a través del lente de la micropolítica de la escuela. En cuanto a problema educativo, pretende visibilizar el papel fundamental que desempeñan los Consejos Escolares en la puesta en acto de las reformas y políticas educativas. Para lograr una comprensión profunda, habrá de tomar en cuenta las reformas y políticas públicas en torno a la gestión escolar y en cómo llegan a los actores en el nivel micro-institucional.

\section{A MANERA DE CIERRE}

La resignificación de reformas y políticas se reconoce como parte del proceso de adopción e implementación de las mismas. Desde el punto de vista de las prácticas sociales dentro del seno escolar, en especial en el marco de los Consejos Escolares, la gestión, la micropolítica y la política educativa a nivel macroinstitucional tienen un fuerte vínculo. La revisión de la literatura sobre las prácticas sociales relacionadas con la autonomía de gestión escolar en el marco de los Consejos Escolares revela que, si bien los primeros estudios provienen de experiencias internacionales, en la actualidad la gran mayoría se concentra en investigaciones mexicanas sobre temas nacionales. Los dos principales campos de indagación son la política educativa y la gestión educativa, con conceptos compartidos de manera reiterada como gestión, trabajo colaborativo, educación básica, docentes, cultura escolar y reforma. Las dimensiones prioritarias en todos los 
casos son la psicológica, social, política, pedagógica, organizacional y profesional. Los problemas investigados desde la política educativa se enfocan en la adopción de políticas, en la implementación de las mismas y en la micropolítica; mientras que, desde la gestión educativa, se orientan a la autonomía, la organización escolar, la formación, la inclusión, la interculturalidad y la evaluación.

Sin embargo, en la literatura revisada no se han detectado estudios de micropolítica que destaquen la puesta en acto de reformas y políticas, entendida ésta como un proceso más complejo que la adopción e implementación que toma en cuenta fuerzas, interacciones y especificidades tanto a nivel macro como micro. Al considerar esos elementos, se vuelve primordial identificar la manera en que micropolítica, organización y autonomía escolar se relacionan con la puesta en acto y visibilizar el papel que desempeńan los Consejos Escolares en el proceso de resignificación de las reformas y políticas en materia de gestión escolar.

La relevancia de la investigación cualitativa a la que pertenece este estado del conocimiento va de la mano con los vacíos detectados en la literatura. En cuanto a problema de investigación, es un aporte sobre el entendimiento del vínculo entre política y gestión educativa visto a través del lente de la micropolítica de la escuela. En cuanto a problema educativo, visibiliza el papel fundamental que desempeñan los Consejos Escolares en la puesta en acto de las reformas y políticas educativas, con efectos previsibles, en específico, sobre la calidad y equidad educativas. El presente estado del conocimiento apoya el objetivo general de la investigación marco: analizar los significados que construyen los actores de la micropolítica en las escuelas públicas estudiadas al poner en acto las políticas y reformas en torno a la autonomía de gestión escolar en el espacio de los Consejos Escolares; así como los específicos: definir las prácticas sociales resultantes del Consejo Escolar ante la puesta en acto de reformas y políticas en torno a la autonomía de gestión escolar; esbozar a nivel de la micropolítica cómo se recrean las reformas y políticas en torno a la autonomía de gestión escolar en el espacio de los Consejos Escolares, y esbozar a nivel de la micropolítica cómo se permean las reformas y políticas en torno a la autonomía de gestión escolar orientadas a la calidad y equidad educativas. 


\section{REFERENCIAS BIBLIOGRÁFICAS}

Descentralización, regulaciones y modelos de autonomía. (2003). Revista Mexicana de Investigación Educativa, 8(18), 291-338.

Abu-Duhou, I. (1999). School-based Management. París: UNESCO-IIEP.

Arzola, D. M. (2014). La distancia entre el discurso de la participación y las prácticas participativas en los centros de educación secundaria. Revista Mexicana de Investigación Educativa, 19(61), 511-535.

Astiz, F. (2006). School Autonomy in the Province of Buenos Aires, Argentina: Evidence from Two School Districts. Comparative Education, 42(2), 203-223.

Ávila, L. A., Hernández, A. K., Echeverría, M. R., y Zambrano, A. (2016). El acompańamiento a docentes de educación básica para nińos jornaleros migrantes y desarrollo docente. Innovación Educativa, 16(71), 111-131. Recuperado de https://www.redalyc.org/ pdf/1794/179446997006.pdf

Ball, S. (1994). La micropolítica de la escuela. Hacia una teoría de la organización escolar. España: Centro de Publicaciones del M.E.C.-Ediciones Paidós Ibérica.

Ball, S., Maguire, M., y Braun, A. (2017). How Schools do Policy? Policy Enactments in Secondary Schools. Nueva York: Routledge.

Bandur, A. (2012). School-based management developments and partnership: Evidence from Indonesia. International Journal of Educational Development, 32(2), 316-328. https://doi.org/10.1016/j.ijedudev.2011.05.007

Brocato, F. (1990). Don't look for a panacea with site based management. Journal of Instructional Psychology, 17(4), 243-251. Recuperado de http://search.ebscohost.com/login.aspx?direct=true $\& \mathrm{db}=\mathrm{a} 9 \mathrm{~h} \& \mathrm{AN}=9$ 607242184\&site=ehost-live

Carrasco, M., Carro, A., y Hernández, F. (2017). La función directiva y el fortalecimiento de la autonomía de gestión. Un estudio en escuelas primarias del estado de Tlaxcala, México. Indivisa. Boletín de Estudios e Investigación, (17), 69-92.

Carro, A., y Arroyo, L. (2017). Evaluación y seguimiento de los Consejos Técnicos Escolares. Memoria Electrónica del XIV Congreso Nacional de Investigación Educativa. San Luis Potosí, México: COMIE. 
Carro, A., Lima, J. A., y Carrasco, M. (2018). Los Consejos Técnicos Escolares para la inclusión y equidad educativa en la educación básica de Tlaxcala, México. Revista Electrónica Educare, 22(1), 146-175.

Centro de Estudios Educativos, Servicios Integrales de Evaluación y Medición Educativa y Heurística Educativa (CEE, SIEME y HE). (2013). Estándares para la educación básica. Experiencia de mejora continua en escuelas mexicanas del nivel básico, con base en estándares curriculares, de desempeño docente y gestión escolar. Revista Latinoamericana de Estudios Educativos, XLIII(3), 23-72.

Crick, B. (1998). Education for Citizenship and the Teaching of Democracy in Schools. Final Report of the Advisory Group on Citizenship. Londres: Qualifications and Curriculum Authority, DfEE.

Cruz, F. (2007). El Consejo técnico escolar como ritual en la escuela secundaria. Revista Mexicana de Investigación Educativa, 12(34), 841-865.

De León, A., e Infante, J. M. (2014). Una evaluación crítica de una experiencia de Educación Ambiental para la Sustentabilidad en el nivel educativo básico en Nuevo León, México. CPU-e, Revista de Investigación Educativa, (19), 184-212.

Del Castillo, G. (2012). Las políticas educativas en México desde una perspectiva de política pública: gobernabilidad y gobernanza. Magis. Revista Internacional de Investigación en Educación, 4(9), 637-652.

Diario Oficial de la Federación (DOF) (1982). Acuerdo que establece la organización y funcionamiento de las escuelas primarias. México: Gobierno de México. DOF (2016). Lineamientos para la organización y el funcionamiento de los Consejos Técnicos Escolares. México: Gobierno de México.

DOF (2019). Decreto por el que se reforman, adicionan y derogan diversas disposiciones de los artículos 3o., 31 y 73 de la Constitución Política de los Estados Unidos Mexicanos, en materia educativa. México: Gobierno de México Recuperado de https://www.dof.gob.mx/nota_detalle.php?co digo $=5560457 \&$ fecha $=15 / 05 / 2019$.

Encinas, A., y Mercado, R. (2012). Formación docente en la escuela: negociación de significado y micropolítica en colectivos de profesores. Región y Sociedad, XXIV(55), 199-226.

Estrada, C.A. (2012). Funcionamiento del Consejo Técnico y la eficacia escolar. Primer Congreso Internacional de Educación. Ponencia llevada a cabo en el congreso de la Universidad Autónoma de Chihuahua, Chihuahua, México. 
Estrada, M., y Sánchez, O. (2016). Representaciones sobre la participación social en la educación en consejos escolares en el norte de México. Foro de Educación, 14(20), 383-403.

Ezpeleta, J. (1990). El Consejo Técnico: eficacia pedagógica y estructura de poder en la escuela primaria mexicana. Revista Latinoamericana de Estudios Educativos, XX(4), 13-33.

Ferreira, D. D. F., Corrochano, M. C., y Leite, K. C. (2018). Gestão escolar e conselho de escola, que relação é esta? Um estudo em busca de novas formas de cooperação entre escola-comunidade na Região de Sorocaba - SP. EccoS - Revista Cientifica, (38), 173-188. https://doi. org/10.5585/eccos.n38.5876

Fierro, C., y Rojo, S. (1994). El consejo técnico. Un encuentro de maestros. México: SEP.

Flores, V., y García, I. (2016). Apoyos que reciben estudiantes de secundaria con discapacidad en escuelas regulares: ¿Corresponden a lo que dicen las leyes? Revista Educación, 40(2), 35-55.

Galván, L., y Espinosa, L. (2017). Diversidad y prioridades educativas en escuelas multigrado. Estudio de caso en México. Sinéctica, (49), 1-19. Gaziel, H. (2008). Site-based Management: Emergence and Effects: The Case of Israel. ISEA, 36(3), 19-34.

González, J. E. (2014). Una mirada del trabajo colaborativo en la escuela primaria desde las representaciones sociales. Ra Ximhai, 10(5), 115134.

González, A., y García, S. A. (2016). Cotidianidad y violencia en las escuelas primarias de la región otomí de Temoaya: hacia un proyecto de interculturalidad para la paz y la convivencia escolar. Ra Ximhai, 12(3), 101-115.

González, R. M., de la Garza, C. H., y de León, M. E. (2017). Consejos Técnicos Escolares, un espacio de colaboración para evaluar el ejercicio docente en Educación Básica. Revista Electrónica de Investigación Educativa, 19(3), 24-32.

Güven, M., Çam, B., y Sever, D. (2013). Demokrasđ Eğđtđmđ Ve Okul Meclđslerđ Projesđ Uygulamalarinin Ve Kazanimlarinin Değerlendđrđlmesđ. Electronic Journal of Social Sciences, 12(46), 1-23. Hammad, W. (2013). The Rhetoric and Reality of Decentralisation Reforms: The Case of School-Based Management in Egypt. ISEA, 41(2), $33-47$. 
Hannan, D. (1998). Reports of effective school councils. Londres, Reino Unido: $S / P$.

Instituto de Investigaciones para el Desarrollo de la Educación (Inide) (2018). Politica Educativa. México: Universidad Iberoamericana. Recuperado de http://inide.ibero.mx/linea-de-investigacion/politicapublica-en-educacion/

Jiménez, L. (2003). La reestructuración de la escuela y las nuevas pautas de regulación del trabajo docente. Revista Mexicana de Investigación Educativa, 8(19), 603-630.

Jiménez, M. L., y Perales, F. J. (2007). Entre proyectos personales y propuestas operativas. Revista Mexicana de Investigación Educativa, 12(35), 1309-1328.

Keene, T. W. (1980). School-Based Management: Missing Link in Accountability. Education, 101(1), 32-37.

Landín, M. R., y Sánchez, S. I. (2016). El trabajo colegiado, un espacio para narrar las experiencias desde la práctica docente. Entreciencias: diálogos en la Sociedad del Conocimiento, 4(11), 343-360.

Latapí, P. (2004). La SEP por dentro. México: Fondo de Cultura Económica. Leer, J. (2016). After the Big Bang: Estimating the effects of decentralization on educational outcomes in Indonesia through a difference-indifferences analysis. International Journal of Educational Development, 49, 80-90. https://doi.org/10.1016/j.ijedudev.2016.02.005

Marques, L. R. (2012). A eleição de diretores nas políticas de democratização da educação na região metropolitana do Recife. Educação Unisinos, 16(2). https://doi.org/10.4013/edu.2012.162.06

Martínez, I. (2016). La convivencia intercultural pacífica en la Telesecundaria No. 0180 "Josué Mirlo". Ra Ximhai, 12(3), 79-99.

Martínez, E., y Moreno, T. (2017). La colegialidad docente en la escuela primaria mexicana: Análisis de sus prácticas. Revista Electrónica Educare, 21(2), 130-150.

Martínez, R., y Vega, S. (2007). Un acercamiento al impacto de Carrera Magisterial en la educación primaria. Revista Latinoamericana de Estudios Educativos, XXXVII(1-2), 91-114.

Mitchell, R. (2017). Democracy or control? The participation of management, teachers, students and parents in school leadership in Tigray, Ethiopia. International Journal of Educational Development, 55, 49-55. https://doi.org/10.1016/j.ijedudev.2017.05.005 
Mondragón, E. (2017). Entre pairos y derivas: realidades de dirección en los Consejos Técnicos Escolares (CTE). Memoria Electrónica del XIV Congreso Nacional de Investigación Educativa. San Luis Potosí, México: COMIE.

Montero, A. (2010). Dirección profesional y selección de directores en el sistema educativo español. Revista Española de Pedagogía, LXVIII(247), 417-435.

Namo, G. (1991). Autonomía de la escuela: posibilidades, límites y condiciones. Boletín 26. Proyecto Principal de Educación en América Latina y el Caribe. Chile: UNESCO-OREALC, pp. 7-24.

Okitsu, T., y Edwards, D. B. (2017). Policy promise and the reality of community involvement in school-based management in Zambia: Can the rural poor hold schools and teachers to account? International Journal of Educational Development, 56, 28-41. https://doi. org/10.1016/j.ijedudev.2017.07.001

Olivo, M., Alaníz, C., y Reyes, L. (2011). Crítica a los conceptos de gobernabilidad y gobernanza. Una discusión con referencia a los consejos escolares de participación social en México. Revista Mexicana de Investigación Educativa (RMIE), 16(50), 775-799.

Ortega, M. (2017). Aprendizajes en Consejo Técnico Escolar: voces docentes hacia una efectiva gestión educativa. Memoria Electrónica del XIV Congreso Nacional de Investigación Educativa. San Luis Potosí, México: COMIE.

Ortega, M., y Hernández, Z. (2017). Eficacia de los Consejos Técnicos Escolares desde las maestras y maestros de educación básica. Memoria Electrónica del XIV Congreso Nacional de Investigación Educativa. San Luis Potosí, México: COMIE.

Ortiz, O., Viramontes, E., y Guevara, A. (2015). La formación docente en el área de lenguaje en el preescolar. Ra Ximhai, 11(4), 241-253.

Perales, F., y Escobedo, M. (2016). La participación social en la educación: entre propuestas innovadoras y tradición educativa. Revista Electrónica de Investigación Educativa, 18(1), 69-81.

Pérez-Ruiz, A. (2014). Enfoques de la gestión escolar: una aproximación desde el contexto latinoamericano. Educación y Educadores, 17(2), 357-369.

Pérez-Ruiz, A. (2017). El sentido de la participación docente en escuelas de tiempo completo. Un estudio de caso. Profesorado. Revista de Currículum y Formación de Profesorado, 21(2), 49-66. 
Rivero, L. (2016). Autonomía de gestión de las escuelas: la ilusión del poder de decisión. Nexos. Recuperado de http://educacion.nexos.com. $\mathrm{mx} /$ wp-content/uploads/2016/01/11.jpg

Robkob, S. (2006). Efficiency of school-based management of basic educational institutions under the jurisdiction of the Office of Nakhon Pathom Education Area 1. Kasetsart Journal Social Sciences, 27(1), 9-18.

Rubio, N. (2017). Los Consejos Técnicos Escolares: asumir las expectativas formales y animar la re-creación de las prácticas. Memoria Electrónica del XIV Congreso Nacional de Investigación Educativa. San Luis Potosí, México: COMIE.

Rubio, M., Castro, G., y Félix, V. (2015). Una aproximación a los procesos formativos del futuro docente de educación primaria. Ra Ximhai, 11(4), 381-402.

Sánchez, M., y Corte, F. (2014). Un estudio sobre la intensificación y la extensión de las jornadas de trabajo. El caso de los maestros de español en Tlaxcala. Revista Latinoamericana de Estudios Educativos, XLIV(2), 73-117.

Santibañez, L., Abreu-Lastra, R., y O’Donoghue, J. L. (2014). School based management effects: Resources or governance change? Evidence from Mexico. Economics of Education Review, 39, 97-109. https://doi. org/10.1016/j.econedurev.2013.11.008

Santizo, C. (2011). Gobernanza y participación social en la escuela pública. Revista Mexicana de Investigación Educativa (RMIE), 16(50), 751-773.

SEP (2016a). El Modelo Educativo 2016. México: SEP.

SEP (2016b). Los fines de la educación en el siglo XXI. México: SEP.

Silas, J. C. (2017). La práctica de la autonomía de gestión desde los actores del Consejo Técnico Escolar. Memoria Electrónica del XIV Congreso Nacional de Investigación Educativa. San Luis Potosí, México: COMIE. Silva, G., y Miranda, M. L. (2017). Implementation and Functioning of School Councils: Difficulties, Potentials and Challenges. Revista Iberoamericana de Educación, 73(2), 23-43.

Solís, S. S., Valenzuela, K. G., y García-Poyato, J. R. (2017). El Consejo Técnico Escolar: perspectiva de distintos actores educativos de nivel primaria ante su funcionamiento. Memoria Electrónica del XIV Congreso Nacional de Investigación Educativa. San Luis Potosí, México: COMIE. 
Tapia, M. (2003). Estado inicial de las escuelas primarias de educación indígena del Programa Escuelas de Calidad: los indicadores de la línea de base. Revista Latinoamericana de Estudios Educativos, XXXIII(4), $97-$ 130.

Tapia, M. (2011). Evaluación de la implementación del programa de enseñanza vivencial de las ciencias en educación básica en Tamaulipas. Revista Latinoamericana de Estudios Educativos, XLI(1-2), 229-260.

Waxman, H. C. (1985). Research on School-Based Improvement Programs: Its Implications for Curriculum Implementation. Education, 105(3), 318-322.

Weiss, E. (2016). La apropiación de una innovación. La hora de Orientación y tutoría en escuelas secundarias. Revista Electrónica de Investigación Educativa, 18(2), 1-26.

Zorrilla, M. (2002). Diez años después del Acuerdo Nacional para la Modernización de la Educación Básica en México: Retos, tensiones y perspectivas. Revista Electrónica de Investigación Educativa, 4(2), 1-1 